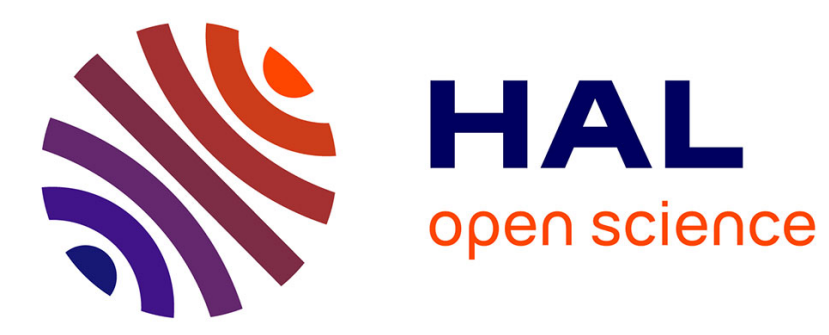

\title{
Analysis of balms taken from Egyptian human mummies using solid-phase extraction and gas chromatography-mass spectrometry
}

Elodie Mezzatesta, Annie Perraud, Cathy Vieillescazes, Carole Mathe

\section{- To cite this version:}

Elodie Mezzatesta, Annie Perraud, Cathy Vieillescazes, Carole Mathe. Analysis of balms taken from Egyptian human mummies using solid-phase extraction and gas chromatography-mass spectrometry. Journal of Separation Science, 2021, 44 (4), pp.850-859. 10.1002/jssc.202000746 . hal-03173550

\section{HAL Id: hal-03173550 \\ https://hal.science/hal-03173550}

Submitted on 19 Apr 2021

HAL is a multi-disciplinary open access archive for the deposit and dissemination of scientific research documents, whether they are published or not. The documents may come from teaching and research institutions in France or abroad, or from public or private research centers.
L'archive ouverte pluridisciplinaire HAL, est destinée au dépôt et à la diffusion de documents scientifiques de niveau recherche, publiés ou non, émanant des établissements d'enseignement et de recherche français ou étrangers, des laboratoires publics ou privés. 
1 Analysis of balms taken from Egyptian human mummies using Solid Phase 2 Extraction and GC-MS

3

\author{
Elodie Mezzatesta ${ }^{1^{*}}$, Annie Perraud ${ }^{2}$, Cathy Vieillescazes ${ }^{1}$, Carole Mathe $^{1^{*}}$ \\ ${ }^{1}$ IMBE UMR7263/ IRD237, Avignon University/ CNRS/ IRD/ Aix-Marseille University, \\ Restoration Engineering of Natural and Cultural Heritage F-84000, Avignon, France.
2 Paul Valéry-Montpellier 3 University. UMR 5140 Archaeology of Mediterranean Societies, team Nilotic and Mediterranean Egypt, Montpellier, France.

Running title : Identification of balms taken from Egyptian human mummies

*Corresponding author: Carole Mathe : carole.mathe@univ-avignon.fr. Avignon Université - UFR-ip STS, Campus Jean-Henri Fabre -Pôle Agro\&Sciences, 301 rue Baruch de Spinoza -BP 21239, 84916 Avignon Cedex 9. Tel. : +33(0)490 144454 Fax : +33(0)490144 439

N,O-Bis (trimethylsilyl)trifluoroacetamide : BSTFA; Dicarboxylic fatty acids : DC; Dichloromethane : DCM; Diethylether : DEE; Dehydroabietic acid : DHA; Dehydroabietic methyl ester : DHAM; Monocarboxylic fatty acids : MC; Tetrahydrofuran : THF; Trimethylchlorosilane : TMCS

Keywords: Balm; Bitumen; Beeswax; Resins, Mummies.

\begin{abstract}
The aim of this paper is to establish a protocol by Solid Phase Extraction-Gas Chromatography-Mass Spectrometry leading to a wide and fine qualitative chemical characterization of the several natural substances present in human mummies' balms, using a minimal quantity of samples. In this study, nine samples were analyzed from mummies dating back from the Third Intermediate Period to the Roman Period, and were provided by the Confluences Museum (Lyon, France). Using Solid Phase Extraction, three fractions were examined in this protocol. The first one, eluted with hexane, concerned chemical families of hydrocarbons of bitumen. The second, eluted with ethanol, enabled terpenic compounds to be characterized and beeswax. The last one, composed of diethyl ether with $2 \%$ of acetic acid, extracted carboxylic acids with a long aliphatic chain (fatty matter) and glycerides. This study also allowed the characterization of non-saponified compounds from beeswax to be obtained while excluding the common saponification step. The analyzed mummification balms were shown to contain fatty matter, beeswax, bitumen and diterpenic resinous material. This one-pot Solid Phase Extraction-Gas Chromatography-Mass Spectrometry method was efficient in reducing both the number of analytical steps and the complexity of the archaeological balms subsequently analyzed by GC-MS.
\end{abstract}


Mummification was a fundamental part of funerary practice in ancient Egypt. The Egyptians believed in immortality and rebirth in the afterlife and in order to be able to access this afterlife, it was necessary to preserve the deceased body. The application of balms was a key part of the mummification process in ensuring successful and lasting preservation of the body [1]. Before applying these balms, however, several steps of the complex process of mummification were carried out. Firstly, an excerebration was performed, followed by evisceration of the thoracoabdominal cavity, before dehydrating the entire body using natron. The complete process of mummification (including evisceration, dehydration and bandaging) took 70 days; within this period and after dehydration by natron, balms could be added inside the eviscerated cavities (thorax, abdomen) and the skull, and then all over the body which would subsequently be bandaged. However, the entire process could vary for each mummy, depending on various factors. All these stages were described by Herodotus (L'Enquête, II, 85-88) [2] and Diodorus Siculus (Bibliothèque historique, I, 21) [3] and could differ according to the period and to the status of the deceased individuals.

Many varieties of natural substances were used in the formulation. These substances have certain pharmacological properties such as being hydrophobic, antibacterial, antifungal and odoriferous. The most frequently used substances were plant oils or animal fats, di- or triterpenic resins, beeswax, bitumen and spices [4-8]. The fatty substances, composed of esters of fatty acids with long chain between 12 and 24 carbon atoms, were used for their hydrophobic properties, the most abundant generally being palmitic $(\mathrm{C} 16: 0)$ and stearic $(\mathrm{C} 18: 0)$ acids. Sterols such as cholesterol are considered as a marker of animal fat, and campesterol as a marker of plant oils [9-11].

Plant resins were used in the formulation of balms for their antibacterial properties. They are composed of terpenic compounds secreted by certain plants [5,12].

Using beeswax limited rehydration of the embalmed body. Beeswax is composed of esters of palmitate with a very long carbon chain alcohols (from 22 to 34 carbon atoms) [13,14]. Bitumen was used for its hydrophobic properties provided by three different apolar chemical families corresponding to linear alkanes and triterpenoids such as sterane and hopane compounds [15-17].

Identifying all of the compounds present in each balm plays an important role in the understanding of archaeological data. Furthermore, such identification represents a significant challenge because of the various chemical reactions such as oxidation and hydrolysis, which can occur naturally over time (aging) or because of anthropogenic factors, such as the heating temperature.

Compounds of alteration can play an important part in identifying plant species. The molecular composition of samples can provide information on the nature of the constituents, the state of conservation of the sample and the treatment undergone by the material during the preparation and/or the formation of balms [18-20]. To identify their composition, the most widespread analytical method described in the literature is Gas Chromatography coupled to Mass Spectrometry (GC-MS) [21-28] because it allows a large number of organic compounds from a complex matrix, even in traces, to be separated and identified.

However, some chemical families, like bitumen, were difficult to accurately characterize because of their low concentration and of the high proportion of fatty acids present in the balms under study. Thus, because of the presence (i) of a 
mixture of natural substances, (ii) of alteration processes, (iii) of a very low proportion of some ingredients or, on the contrary, a high concentration of others, the use of GC-MS is often preceded by several sample pre-treatments. A pre-treatment sample was often necessary, such as saponification reactions for the detection of waxes $[29,30]$, dichloromethane or diethyl ether extractions for the detection of free fatty acids and terpenic compounds, as well as fractionation for hydrocarbons $[6,26,29,31-35]$. All of these pre-treatments enable a fine chemical characterization of samples to be obtained, but pre-treatments also create the need for more archaeological material mass, when the quantities available for analysis are generally small.

The aim of this study therefore, was to develop a single and efficient protocol by SPE-GC-MS. The main objective of this paper is to determine the fine chemical composition of nine mummification balms and to reduce the number of experimental steps, thus reducing the amount of archaeological sample used thanks to a one-pot procedure.

\section{Materials and Methods}

\subsection{Archaeological samples}

Within the framework of a multidisciplinary research project entitled Human Egyptian Lyon Confluences Mummies (HELYCOM)-Mourir pour renaitre, mummification balms of 9 human mummies were analyzed. In this research work, female and male mummies from Upper Egypt (around Thebes) dating from $600 \mathrm{BC}$ to the Roman Period ( $300 \mathrm{AD}$ ) were studied. In this study, a total of 9 samples belonging to the Egyptian collection of the Confluences Museum in Lyon (France) were examined. The samples referred to as 30000111 (34), 30000139 (15), 30000148 (18), 30000286 (11) and 90001951A (50) were mummified heads, and 90001169 (41), 90001258 (40), 90001259 (47) and 900015978 (66) were provided from complete mummies. The mummies studied were those of men and women dating from the Third Intermediate Period to the Roman Period and coming from different necropolises such as Thebes, Esna, Kom-Ombo and Deir-el-Medineh. The weight of the samples varied from 20 to $200 \mathrm{mg}$. They were collected at different location points on the mummies: on the mummified skin, on the textile covered by balms, or directly within the balm itself (Table 1).

\subsection{Solvents and reagents}

All solvents were of the highest purity grade. Hexane, tetrahydrofuran (THF) and $\mathrm{N}, \mathrm{O}$-Bis (trimethylsilyl)trifluoroacetamide/Trimethylchlorosilane (BSTFA/TMCS) were supplied by Sigma-Aldrich. Ethanol, dichloromethane (DCM) and diethylether (DEE) were supplied by Merck.

\subsection{Saponification}

$10 \mathrm{mg}$ of sample was extracted with $3 \times 1 \mathrm{~mL}$ of THF aided by sonification (5 min) and then centrifuged at $6000 \mathrm{rpm}(5 \mathrm{~min})$. The supernatant was set aside to extract the solid pellet again. The solvent extracts were combined and then $2 \mathrm{~mL}$ of a solution of potassium hydroxide $\mathrm{KOH} 10 \%$ in $\mathrm{MeOH} / \mathrm{H} 2 \mathrm{O}(9 / 1, \mathrm{v} / \mathrm{v})$ were added. The mixture was magnetically stirred and heated at $65^{\circ} \mathrm{C}$ during 1 hour. After evaporation $3 \mathrm{~mL}$ of pure water was added with $1 \mathrm{~mL}$ of $\mathrm{HCl} 5 \mathrm{M}$. The aqueous phase was 
washed with $3 \times 5 \mathrm{~mL}$ of diethyl ether. The organic phases were combined and dried with anhydrous sodium sulphate, then filtered on filter paper. Excess reagent was evaporated to dryness under a stream of nitrogen. Trimethylsilylation was applied. After evaporation, the derivatized sample was solubilized in hexane/DCM mixture $(2 / 1, v / v)$ and filtered on PTFE cartridge before injection in GC-MS.

\subsection{Solid Phase Extraction}

Preliminary tests were realized to determine the best SPE conditions. In this study, according to the apolar properties to the wide chemical compounds present in human mummies' balms, three types of SPE columns were tested: C18, Cyano and Amino phases associated to different solvents of elution (hexane, methanol, ethanol, isopropanol, diethyl ether with $2 \%$ of acetic acid and dichloromethane). The $\mathrm{NH}_{2} \mathrm{SPE}$ column associated to hexane, ethanol, diethyl ether with $2 \%$ acetic acid exhibited the best results so this column was used in this study according to the following protocol.

$10 \mathrm{mg}$ of the sample were extracted with $1 \mathrm{~mL}$ of hexane/tetrahydrofuran (THF) (1/1) using ultrasound for five minutes and then centrifuged at $6000 \mathrm{rpm}$ for five minutes. The supernatant was set aside to extract the solid pellet a second and third time. The three fractions obtained were combined and evaporated to dryness under a stream of nitrogen and the mixture was then dissolved in $500 \mu \mathrm{L}$ hexane/THF $(1 / 1, \mathrm{v} / \mathrm{v})$. This mixture was called the charge.

In parallel, an SPE cartridge strata $\mathrm{NH}_{2} 200 \mathrm{mg} / 3 \mathrm{~mL}$ (Phenomenex) was conditioned in an SPE vacuum manifold with $4 \mathrm{~mL}$ of hexane at a flow of $1.2 \mathrm{~mL} \cdot \mathrm{min}^{-1}$. The charge was deposited on the cartridge. Then a first elution was carried out with $4 \mathrm{~mL}$ of hexane and collected (fraction 1). A second elution was performed with $4 \mathrm{~mL}$ of ethanol and was collected (fraction 2). Finally, a last elution was carried out with 3 $\mathrm{mL}$ of diethyl ether (DEE) including $2 \%$ acetic acid (fraction 3). Each fraction was evaporated to dryness under a stream of nitrogen and then trimethylsilylated with 200 $\mu \mathrm{L}$ of BSTFA/TMCS at $70^{\circ} \mathrm{C}$ during 30 min. Fractions 1 and 2 were solubilized with $60 \mu \mathrm{L}$ hexane/DCM $(2 / 1, \mathrm{v} / \mathrm{v})$ and were injected into GC-MS at temperature gradient No.1. Fraction 3 was solubilized with $1.5 \mathrm{~mL}$ hexane/DCM (2/1) and injected into GCMS by using gradient program No.2.

Each SPE parameter, namely the nature of the sorbent, the dimension of the cartridge, the sampling flow rate, the sample volume, the eluents and the desorption flow rate, was optimized.

\subsection{GC-MS conditions}

A Thermo Scientific Focus gas chromatographic system composed of a Thermo Scientific Al 3000 auto-sampler coupled with an ITQ 700 ion trap mass spectrometer was used (Thermo Fisher Scientific). The GC column was a fused silica capillary column Thermo trace GOLD TG-5MS (5\% diphenyl / 95\% dimethylpolysiloxane, 30 $\mathrm{m}$ length $\times 0.25 \mathrm{~mm}$ i.d. $\times 0.25 \mu \mathrm{m}$ film thickness). Helium was the carrier gas with a constant flow of $1 \mathrm{~mL} \cdot \mathrm{min}^{-1} .1 \mu \mathrm{L}$ of each sample was injected with a splitless time of $1 \mathrm{~min}$. The injector temperature was set at $250{ }^{\circ} \mathrm{C}$. Mass spectra were recorded in electron impact mode with an electron ionization voltage of $70 \mathrm{eV}$, an ionization time of $25,000 \mu \mathrm{s}$ and a mass range of $40-650 \mathrm{~m} / \mathrm{z}$. The transfer line, ion trap and manifold temperatures were respectively set at $300^{\circ} \mathrm{C}, 200^{\circ} \mathrm{C}$ and $50^{\circ} \mathrm{C}$. Detected 
compounds were identified from their retention time and interpretation of their mass spectra in comparison with standard compounds and using NIST database. The oven temperature was programmed as follows:

- Temperature gradient No.1: $160^{\circ} \mathrm{C}$, isothermal for one minute, then increased by $10{ }^{\circ} \mathrm{C} \cdot \mathrm{min}^{-1}$ up to $180{ }^{\circ} \mathrm{C}$, constant for three minutes, followed by a second increase of $3^{\circ} \mathrm{C} \cdot \mathrm{min}^{-1}$ up to $260^{\circ} \mathrm{C}$, constant for five minutes, followed by a third increase of $2.5^{\circ} \mathrm{C} \cdot \mathrm{min}^{-1}$ up to $300^{\circ} \mathrm{C}$ and finally, a final increase of $10^{\circ} \mathrm{C} \cdot \mathrm{min}^{-1}$ up to $320^{\circ} \mathrm{C}$, the temperature of which was maintained for three minutes. The total analysis time was fifty-nine minutes.

- Temperature gradient No.2: $115^{\circ} \mathrm{C}$, constant for two minutes, then increased by $15^{\circ} \mathrm{C} \cdot \mathrm{min}^{-1}$ up to $220^{\circ} \mathrm{C}$, followed by a second increase of $3^{\circ} \mathrm{C} \cdot \mathrm{min}^{-1}$ up to $250^{\circ} \mathrm{C}$ and finally, a last increase of $10^{\circ} \mathrm{C} \cdot \mathrm{min}^{-1}$ up to $320^{\circ} \mathrm{C}$, the temperature of which was maintained for three minutes. The total analysis time was twentynine minutes.

\section{Results and discussion}

Owing to (i) the hypothetical occurrence of well-known natural substances, such as fatty matter or plant resins and (ii) to the presence of alcohol and/or carboxylic functional groups, the selected cartridge was the Strata $\mathrm{NH}_{2}$. It effectively allows the retention of compounds depending on the electrostatic attractions of the functional groups of the compounds of interest to the $\mathrm{NH}_{2}$ grouping, bound at the surface of the SPE cartridge. The SPE protocol was carried out according to the schema described in Figure 1. All of the molecules detected in the nine archaeological samples are listed in Table 2.

\subsection{Tetrahydrofuran solubilization}

Solubilization of the sample is necessary beforehand, since depositing the solid matter directly on the SPE cartridge percolates the cartridge and inhibits elution. The solvent must facilitate the most exhaustive possible extraction of the compounds of interest, both qualitatively and quantitatively. Under these experimental conditions, the solvent should be moderately apolar in order to extract the compounds present in the balms. Several tests were carried out, comparing them with solvents usually described in the specialized literature, such as dichloromethane and diethyl ether. Tetrahydrofuran/hexane (1/1) was chosen owing to a polarity close to that of chloroform or dichloromethane, but it is a water-miscible solvent and it should therefore have superior capacities for the solubilization of polar molecules [36].

\subsection{Fraction 1}

The first eluted fraction was carried out using hexane, which is the most apolar solvent used in this study. This elution was start with an apolar solvent because the stationary phase is a polar phase, moreover, hexane is also the conditioning solvent of the cartridge. Hexane was able to elute the most apolar molecules present in the studied balms, such as aliphatic molecules, linear, branched, cyclized alkanes or polycyclic aromatic hydrocarbons (PAHs). An illustration of the obtained results in Sample No.18 is presented in Figure 2. The detection of the three chemical families of bitumen at $m / z 57$ (alkanes), $m / z 191$ (hopane) and $m / z 217$ (sterane) can be used for the characterization of bitumen [9]. The chemical families of hopanes and 
steranes existed in only a very low proportion in bitumen (5\%), the characterization of these chemical families thus usually requiring special treatment [37]. Identification of archaeological bitumen was generally performed by isolating and splitting the several compounds depending on their nature: saturated hydrocarbons, aromatic hydrocarbons, and other compounds using column chromatography [38,39].

The GC-MS analyses of Fraction 1 of the samples referred to as 34, 15, 18, 41 and 50 resulted in the detection of occurrence of the three chemical families of bitumen: alkanes, hopanes and steranes. These results confirmed the presence of bitumen in the balms under study.

In addition to these results, a PAH was detected and identified to retene. An anthropic degradation of Pinaceae resin such as thermal degradation can be deduced from the detection of retene. This latter molecule was formed mainly under very high temperatures [40] and its occurrence was observed in 5 balms and in a significant proportion in the balm of Sample 11. Contrary to the other diterpenic compounds eluted in the fraction 2, retene was identified in the fraction 1 because of its apolar property.

\subsection{Fraction 2}

Fraction 2, eluted with ethanol enabled most polar compounds such as diterpenoids, which are functionalized compounds, to be eluted, with the occurrence of alcohol, carboxylic acid, ketone, or aldehyde functions [9].

Diterpenic resin was detected in 8 out of 9 samples $(34,15,18,11,41,40,47$ and 66). For example, the sample referred to as 18 had many diterpenoids, which are characteristic of the use of Pinaceae resin, such as in the elution order: dehydroabietic acid (DHA, Rt=23.13 $\mathrm{min})$, 7-hydroxy-DHA ( $\mathrm{Rt}=24.5 \mathrm{~min})$ and 7-oxo$\mathrm{DHA}$ (Rt=26.3 min) (Figure 3). During the aging process, an initial predominant isomerization produces dehydroabietic acid. A natural degradation of this acid could occur the formation of products such as 7-oxo-DHA, 7-oxo-15-hydroxy-DHA [41-43]. Additionally, to the diterpenoids already identified, another compound, dehydroabietic methyl ester (DHAM, Rt $=20.5 \mathrm{~min}$ ), was characterized in both of the samples referred to as 18 and 11 . This molecule is produced by methanolysis. In fact, during heating at a very high temperature, resinous wood releases methanol, which reacts with the carboxylic acids of diterpenoids and this reaction leads to the formation of the corresponding methyl ester derivatives. DHAM allows wood tar to be characterized and this compound is totally absent when resin alone is heated [44].

Moreover, palmitate esters corresponding to unsaponified beeswax molecules were identified in this fraction ( $\mathrm{Rt}=55-58 \mathrm{~min}$ ). Beeswax does not necessarily undergo hydrolysis with aging, and its molecules therefore can remain in their ester form [45]. In this eluted fraction, the presence of beeswax was directly characterized in samples $34,15,18,66,50$ and 47 . The characterization of beeswax is usually performed by initially carrying out a pre-treatment of the samples corresponding to a reaction of saponification [29]. With the purpose of confirming either presence or absence of beeswax, saponification was performed as a preliminary step. Results obtained through saponification are in accordance with aforementioned SPE-GC-MS data [36]. In order to interpret the elution phenomenon of these apolar compounds in ethanol, it is necessary to consider the state of ionization of the several compounds and also to consider the occurrence of free fatty acids in the mixture. In this solution, the stationary amine phase was in the $\mathrm{NH}_{3}{ }^{+}$form and free fatty acids were in the $\mathrm{COO}^{-}$ form, enabling ionic bonds therefore to be formed between the two forms and thus creating a type of semi-apolar grafted phase in the cartridge. Beeswax esters could 
form Van der Waals bonds (London interactions) with the carbon chain of free fatty acids, which would explain why they are not eluted with hexane in Fraction 1. The subsequent addition of ethanol, a protic solvent, capable thus of generating hydrogen bonds, could create an imbalance leading to the elution of esters.

\subsection{Fraction 3}

Fraction 3 was eluted with a mixture of diethyl ether with $2 \%$ acetic acid. In this experimental condition, carboxylic acids presented $\mathrm{COOH}$ functions, and the amine of the stationary phase was in $\mathrm{NH}_{3}{ }^{+}$form. No ionic bond was formed between these two chemical forms. For this reason, this fraction allowed fatty acids to be eluted. All samples contained monocarboxylic fatty acids (MC) and/or dicarboxylic acids (DC). An illustration of the obtained results in sample 18 is presented in Figure 4 . In the obtained GC-MS chromatograms, the relative proportion of MC represented on average, approximately $50 \%$ of the total composition of balms and this percentage could attain $90 \%$ depending on the archaeological sample studied. This relative percentage was calculated from the peak area of each detected compound from corresponding chromatograms. Monocarboxylic acids corresponded also to the main chemical compounds present in all of the analyzed balms.

Saturated monocarboxylic acids cannot provide much information in the archaeological context about the origin of the fat matter used. In fresh material, it is possible to examine the peak area ratio of MC 16:0/MC 18:0 (palmitic acid/stearic acid) to determine the nature of the fatty matter [9]. However, this method is not applicable in an archaeological context because the proportions of these molecules can change with the state of degradation of the material or can even be caused by a mixture of oils and fats. This method is therefore not suitable for the analysis of mummy balms. The same is true for the proportions of saturated fatty acids with a short carbon chain. They fail to provide much information because these molecules are certainly the result of fat/oil degradations.

In this study using GC-MS, therefore, the animal or plant nature of fats cannot be accurately defined because biomarkers of plant oils and/or animal fats were not detected. Owing to the use of GC-MS in archaeological context, the objective of this paper was not to determine the nature or the origin of the fatty matter (i.e. fatty acids and glycerides). Cholesterol was only detected in the samples referred to as 34, 11 and 40. The occurrence of this molecule did not allow animal origins to be identified with certainty because the occurrence could result from an external contamination of the deceased by capillarity or of a contemporary contamination during the transport or the storage of the objects. Samples 15, 18, 41, 4766 and 50 contained numerous dicarboxylic acids. These types of acids were markers of degradation of fatty substances. Unsaturated fatty acids can undergo oxidation and form hydroperoxide intermediates to finally generate short monocarboxylic acids and dicarboxylic acids [10].

\section{Conclusion}

The studied mummification balms contained fatty matter, beeswax, bitumen and diterpenic resin. This efficient SPE-GC-MS protocol has thus enabled additional substances to be identified, substances such as hopanes and steranes of bitumen and palmitate esters of beeswax. It has also enabled markers of wood tar such as DHAM compound to be identified and has reduced the number of experiments such as the long pre-treatment of saponification or the splitting of the constituents of bitumen. The quantity of samples has also been reduced, which is very interesting 
from an archaeological point of view given the very small amount of material available, in accordance with cultural heritage directives concerning preservation. This developed SPE protocol as applied to human balms of mummies has enabled each ingredient of the studied balms to be separated and concentrated. Moreover, this multiple extraction/partial elution, carried out during a single experimentation, has resulted in better pre-separation of the compounds deriving from a large panel of natural substances used in Ancient Egypt. The SPE protocol described in this study was also successfully applied and performed in the analyses of 61 samples taken from 43 human mummies from Upper Egypt [36].

\section{Acknowledgments}

The authors acknowledge the anonymous reviewers for their careful reading of our manuscript and their many insightful comments and suggestions. The authors wish to thank the Museum of Confluences in Lyon and the LabEx ARCHIMEDE and Human Egyptian LYon COnfluences Mummies (HELYCOM) - Mourir pour renaître project. A part of this project was supported by LabEx ARCHIMEDE from the Investissement d'Avenir program ANR-11-LABX-0032-01. The research has been funded by a PhD grant given by The French Ministry of Higher Education and Research.

\section{Conflict of interest}

The authors declare that they have no conflict of interest.

\section{References}

[1] Dunand, F., Lichtenberg, R., Les Momies et La Mort En Egypte. 1998.

[2] Barguet, A. (Tran.), Hérodote - Thucydide Oeuvres Complètes. Bibliothèque de la Pléiade, Paris 1964.

[3] Vernière, Y. (Tran.), Diodore de Sicile. Bibliothèque Historique. Les belles lettres, Paris 1993.

[4] Goyon, J. C., Rituels Funéraires de l'ancienne Egypte. Le Rituel de l'Embaumement. Le Rituel de l'Ouverture de La Bouche. Les Livres Des Respirations. Paris 1972.

[5] Nicholson, P. T., Shaw, I., Ancient Egyptian Materials and Technology. 2000.

[6] Colombini, M. P., Modugno, F., Silvano, F., Onor, M., Characterization of the Balm of an Egyptian Mummy from the Seventh Century B.C. Stud Conserv 2000, 45, 19.

[7] Abdel-Maksoud, G., El-Amin, A. R., A review on the materials used during the mummification processes in ancient Egypt. Mediterr. Archaeol. Archaeom. 2011, $11,129-150$.

[8] Marshall, A., Lichtenberg, R., Les Momies Egyptiennes. La Quête Millénaire d'une Technique. 2013.

[9] Clark, K. A., Tracing the Evolution of Organic Balm Use in Egyptian Mummification via Molecular and Isotopic Signatures, PhD Thesis, Bristol, 2006.

[10] Bastien, C., Etude Chimique Des Substances Contenues Dans Une Collection Exceptionnelle de Poteries Provenant de Deir-El-Medineh (Egypte): Une Population et Ses Produits, PhD Thesis, Strasbourg, 2011.

[11] Gea, J., Sampedro, M. C., Vallejo, A., Polo-Díaz, A., Goicolea, M. A., Fernández-Eraso, J., Barrio, R. J., Characterization of ancient lipids in prehistoric organic residues: Chemical evidence of livestock-pens in rockshelters since early neolithic to bronze age. J. Sep. Sci. 2017, 40, 4549-4562. 
[12] Bruni, S., Guglielmi, V., Identification of archaeological triterpenic resins by the non-separative techniques FTIR and 13C NMR: The case of Pistacia resin (mastic) in comparison with frankincense. Spectrochim. Acta A Mol. Biomol. Spectrosc. 2014, 121, 613-622.

[13] Régert, M., Colinart, S., Degrand, L., Decavallas, O., Chemical Alteration and Use of Beeswax Through Time: Accelerated Ageing Tests and Analysis of Archaeological Samples from Various Environmental Contexts. Archaeometry 2001, 43, 549-569.

[14] Régert, M., Langlois, J., Colinart, S., Characterisation of wax works of art by gas chromatographic procedures. J. Chromatogr. A 2005, 1091, 124-136.

[15] Bahn, P. G., The making of a mummy. Nature 1992, 356, 109-109.

[16] Harrell, J. A., Lewan, M. D., Sources of mummy bitumen in ancient Egypt and Palestine. Archaeometry 2002, 44, 285-293.

[17] Connan, J., Kozbe, G., Kavak, O., Zumberge, J., Imbus, K., The bituminous mixtures of Kavuşan Höyük (SE Turkey) from the end of the 3rd millennium (2000BC) to the Medieval period (AD 14th century): Composition and origin. Org. Geochem. 2013, 54, 2-18.

[18] Peters, K. E., Walters, C. C., Moldowan, J. M., The Biomarker Guide: Volume 2, Biomarkers and Isotopes in Petroleum Systems and Earth History. Cambridge University Press 2007.

[19] Evershed, R. P., Organic residue analysis in archaeology: the archaeological biomarker revolution. Archaeometry 2008, 50, 895-924.

[20] Ménager, M., Perraud, A., Vieillescazes, C., Analyse de baumes issus de tête momifiée (Thèbes). Archéosciences, revue d'archéométrie 2013.

[21] Nicholson, T. M., Gradl, M., Welte, B., Metzger, M., Pusch, C. M., Albert, K., Enlightening the past: Analytical proof for the use of Pistacia exudates in ancient Egyptian embalming resins: Gas Chromatography. J. Sep. Science 2011, 34, 3364-3371.

[22] Ribechini, E., Modugno, F., Baraldi, C., Baraldi, P., Colombini, M.P., An integrated analytical approach for characterizing an organic residue from an archaeological glass bottle recovered in Pompeii (Naples, Italy), Talanta. 2008, 74(4), 555-561.

[23] Bonaduce, I., Ribechini, E., Modugno, F., Colombini, M. P., Analytical approaches based on gas chromatography mass spectrometry (GC/MS) to study organic materials in artworks and archaeological objects, Top Curr Chem, 2016, 374(1), 1-37.

[24] Charrié-Duhaut, A., Connan, J., Rouquette, N., Adam, P., Barbotin, C., de Rozières, M.-F., Tchapla, A., Albrecht, P., The canopic jars of Rameses II: real use revealed by molecular study of organic residues. J. Archaeol. Sci. 2007, 34, 957-967.

[25] Bera, S., Dutta, S., Paul, S., Khan, M., Ghosh, R., Dammar resin from the Eocene lignite of Bengal Basin, eastern India: Terpenoid composition and botanical origin. Geobios 2016, 50, 3-8.

[26] Jones, J., Higham, T. F. G., Chivall, D., Bianucci, R., Kay, G. L., Pallen, M. J., Oldfield, R., Ugliano, F., Buckley, S. A., A prehistoric Egyptian mummy: Evidence for an 'embalming recipe' and the evolution of early formative funerary treatments. J. Archaeol. Sci. 2018, 100, 191-200.

[27] Tchapla, A., Méjanelle, P., Bleton, J., Goursaud, S., Characterisation of embalming materials of a mummy of the Ptolemaic era. Comparison with balms from mummies of different eras. J. Sep. Science 2004, 27, 217-234. 
[28] Hamm, S., Bleton, J., Tchapla, A., Headspace solid phase microextraction for screening for the presence of resins in Egyptian archaeological samples. J. Sep. Science 2004, 27, 235-243.

[29] Łucejko, J., Connan, J., Orsini, S., Ribechini, E., Modugno, F., Chemical analyses of Egyptian mummification balms and organic residues from storage jars dated from the Old Kingdom to the Copto-Byzantine period. J. Archaeol. Sci. 2017, 85, 1-12.

[30] Degano, I., Colombini, M. P., Multi-analytical techniques for the study of preColumbian mummies and related funerary materials. J. Archaeol. Sci. 2009, 36, 1783-1790.

[31] Łucejko, J., Lluveras-Tenorio, A., Modugno, F., Ribechini, E., Colombini, M. P., An analytical approach based on X-ray diffraction, Fourier transform infrared spectroscopy and gas chromatography/mass spectrometry to characterize Egyptian embalming materials. Microchem. J. 2012, 103, 110-118.

[32] Ménager, M., Azemard, C., Vieillescazes, C., Study of egyptian mummification balms by FT-IR spectroscopy. Microchem. J. 2014, 114, 32-41.

[33] Jacqueline, S., Bleton, J., Huynh-Charlier, I., Minchin, S., Muller, A. L., Poupon, J., Charlier, P., Histoire Des Sciences Médicales. 2016.

[34] Goyon, J. C., Mathe, C., Vieillescazes, C., A propos de la momie infantile du musée Calvet d'Avignon. ENiM 2016, 135-139.

[35] Brettell, R., Martin, W., Atherton-Woolham, S., Stern, B., McKnight, L., Organic residue analysis of Egyptian votive mummies and their research potential. Stud Conserv. 2017, 62, 68-82.

[36] Mezzatesta, E., Caractérisation Moléculaire de Baumes de Momies Humaines d'Egypte Ancienne., Avignon Université, 2019.

[37] Connan, J., La Momification Dans l'Egypte Ancienne: Le Bitume et Les Autres Ingrédients Organiques Des Baumes de Momies Ou Les Ingrédients Organiques Des Baumes de Momies Égyptiennes: Bitume, Cire d'abeillerésines, Poix, Graisses, Huile, Vin, Etc. 2005.

[38] Charrié-Duhaut, A., Burger, P., Maurer, J., Connan, J., Albrecht, P., Molecular and isotopic archaeology: Top grade tools to investigate organic archaeological materials. C R Chim 2009, 12, 1140-1153.

[39] Hauck, T. C., Connan, J., Charrié-Duhaut, A., Le Tensorer, J. M., Sakhel, H., Molecular evidence of bitumen in the Mousterian lithic assemblage of Hummal (Central Syria). J. Archaeol. Sci. 2013, 40, 3252-3262.

[40] Carpy, A., Marchand-Geneste, N., Molecular characterization of retene derivatives obtained by thermal treatment of abietane skeleton diterpenoids. $\mathrm{J}$. Mol. Struct 2003, 635, 45-53.

[41] Scalarone, D., Lazzari, M., Chiantore, O., Ageing behaviour and pyrolytic characterisation of diterpenic resins used as art materials: colophony and Venice turpentine. J Anal Appl Pyrolysis 2002, 64, 345-361.

[42] Romero-Noguera, J., Bolívar-Galiano, F. C., Ramos-López, J. M., FernándezVivas, M. A., Martín-Sánchez, I., Study of biodeterioration of diterpenic varnishes used in art painting: Colophony and Venetian turpentine. Int. Biodeterior. Biodegradation 2008, 62, 427-433.

[43] Mezzatesta, E., Perraud, A., Vieillescazes, C., Mathe, C., GC-MS and PCA analyses of diterpenoids degradation state in 21 human mummies of Ancient Egypt dating from New Kingdom to Graeco-Roman Period. J Cult Herit. DOI: 10.1016/j.culher.2020.09.008 
[44] Colombini, M. P., Modugno, F., Ribechini, E., GC/MS in the characterization of lipids, in: Colombini, Modugno (Eds.) Organic Mass Spectrometry in Art and Archaeology. 2009, pp 189-213.

[45] Č́́žová, K., Vizárová, K., Ház, A., Vykydalová, A., Cibulková, Z., Šimon, P., Study of the degradation of beeswax taken from a real artefact. J Cult Herit. 2019, 37, 103-112.

Figure captions

Figure 1: Schema of the final Solid Phase Extraction protocol developed with the predominantly detected substances in each elution fraction.

Figure 2: Chromatograms of sample 18, Fraction 1 and extracted signal at $m / z 57$, $\mathrm{m} / \mathrm{z} 191$ and $\mathrm{m} / \mathrm{z} 217$, respectively base peaks of alkanes, hopanes and steranes.

Figure 3: TIC chromatogram of sample 18, Fraction 2.

Figure 4: TIC chromatogram of sample 41, Fraction 3.

Figure 1: Schema of the final Solid Phase Extraction protocol developed with the predominantly detected substances in each elution fraction.

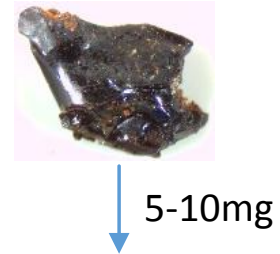

Extraction US $10 \mathrm{~min}$ in $1 \mathrm{~mL}$ THF/hexane $1 / 1$ (X3) Centrifugation $6500 \mathrm{rpm}(5 \mathrm{~min})$

Centrifugation 6500 rpm 15 min 2

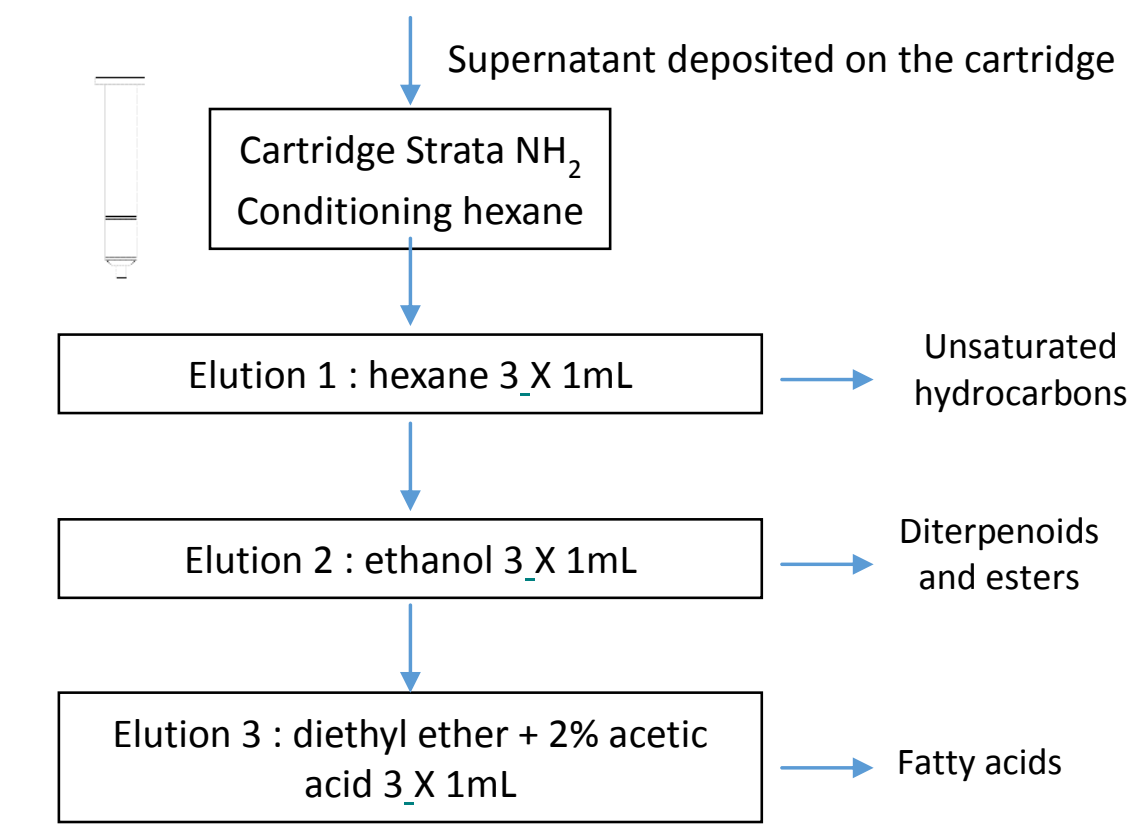


Figure 2: TIC partial chromatogram of sample 18, Fraction 1 and extracted signal at $m / z 57$, $m / z 191$ and $m / z 217$, respectively base peaks of alkanes, hopanes and steranes.

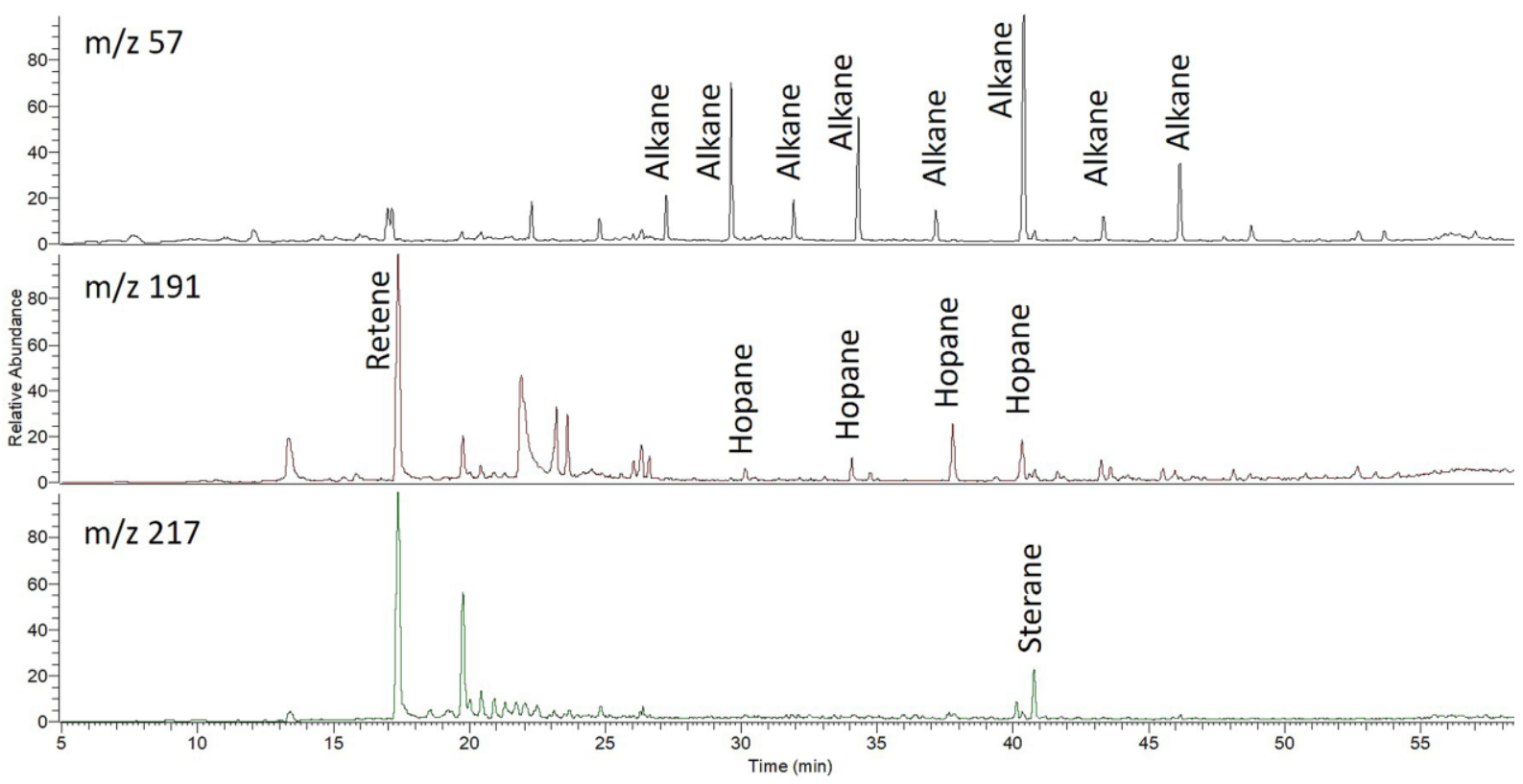


519 Figure 3: TIC Partial chromatogram of sample 18, Fraction 2.

520

521

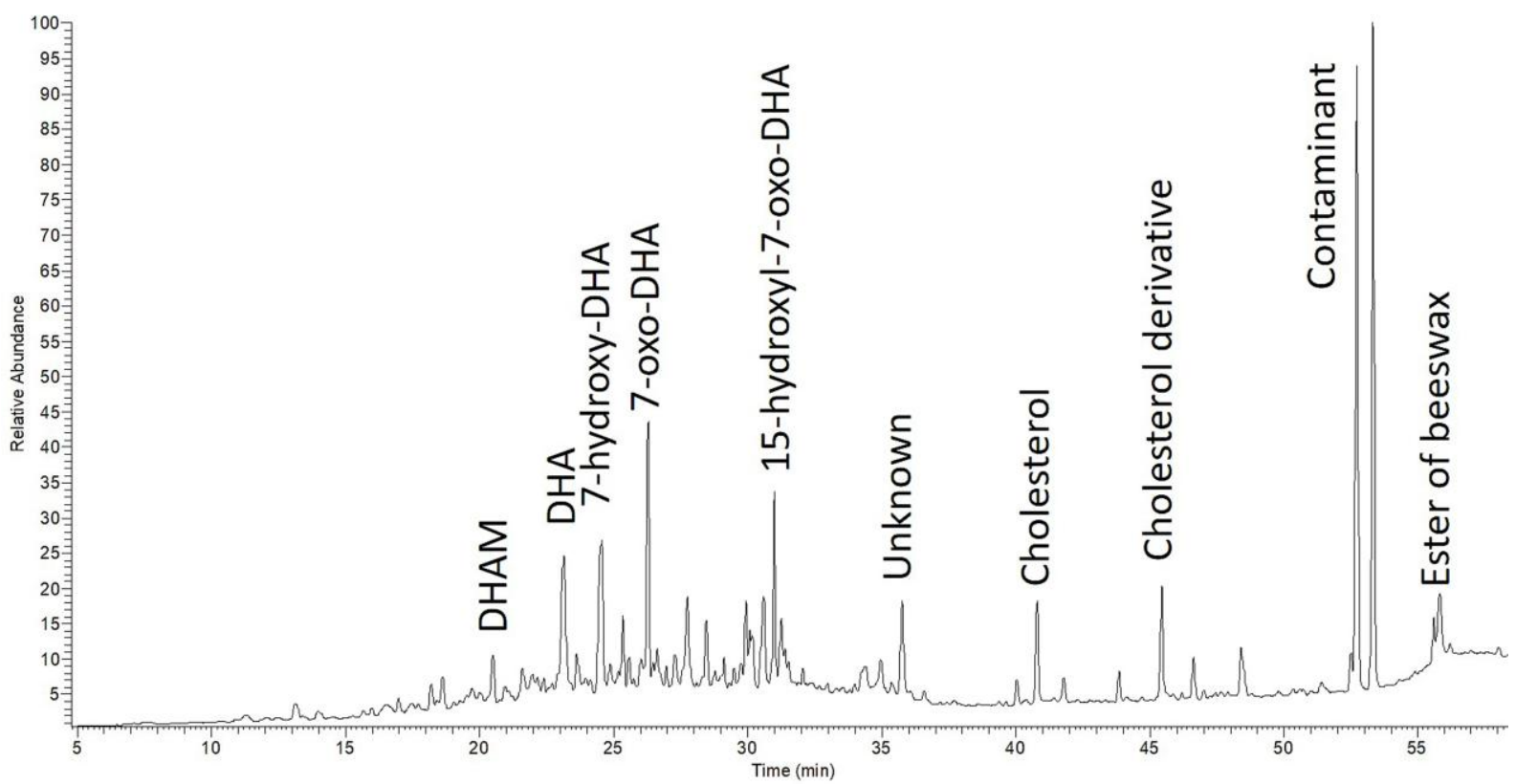

522

523 Figure 4: TIC partial chromatogram of sample 41, Fraction 3

524

525

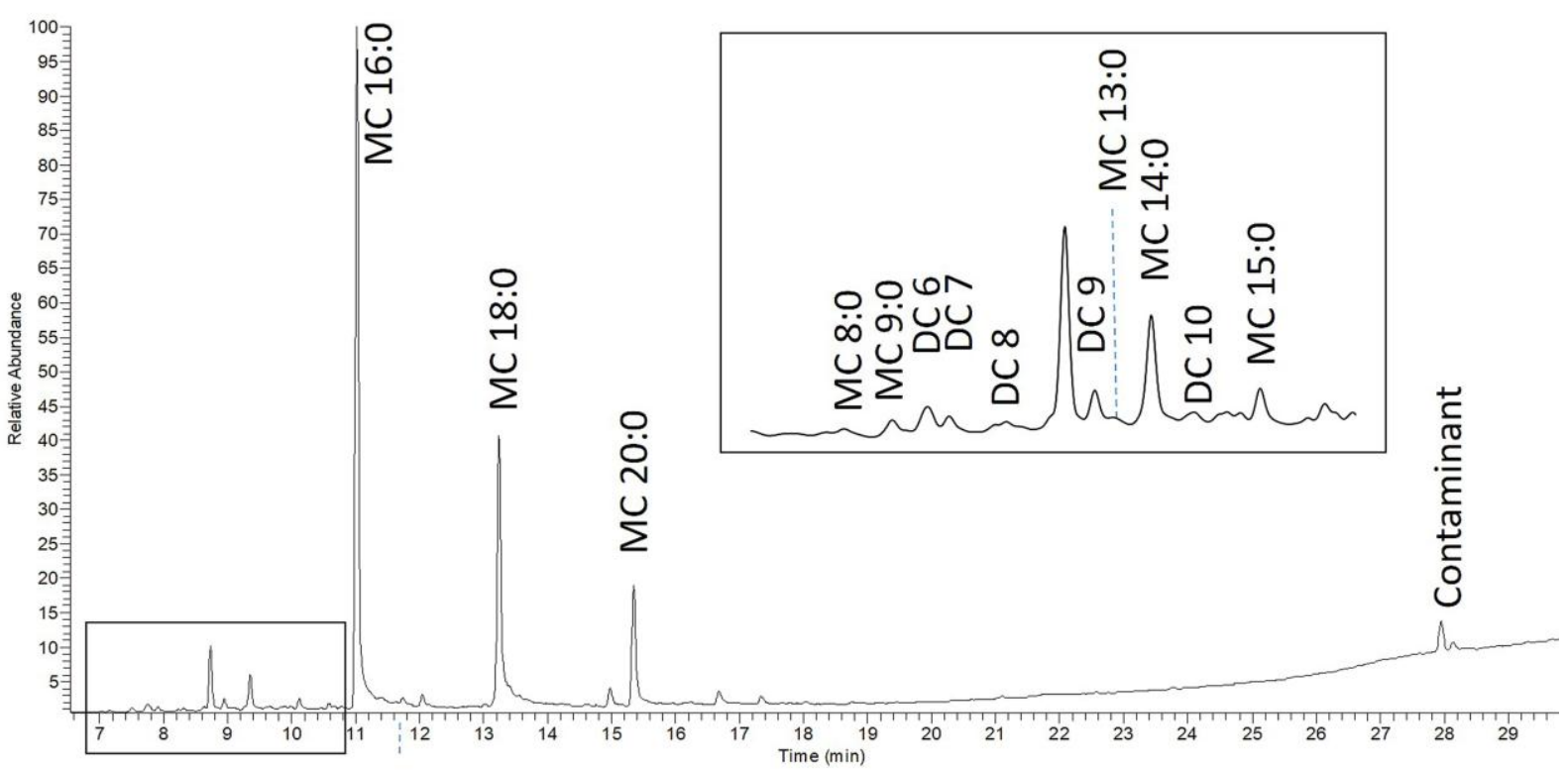

526

527 
528 Table 1: Sample presentation

\begin{tabular}{|c|c|c|c|c|}
\hline $\begin{array}{l}\text { Inventory } \\
\text { no. }\end{array}$ & Lab code & Sex and age & $\begin{array}{l}\text { Site of } \\
\text { excavation }\end{array}$ & Relative dating \\
\hline 30000111 & 34 & Elderly male & Gournah & Graeco-Roman Period \\
\hline 30000139 & 15 & Adult female & Gournah & Ptolemaic to Roman Period \\
\hline 30000148 & 18 & Elderly male & Thebes & Unknown \\
\hline 30000286 & 11 & $\begin{array}{l}\text { Adult or elderly } \\
\text { male }\end{array}$ & Esna & $\begin{array}{l}\text { Third Intermediate Period to } \\
\text { Late Period }\end{array}$ \\
\hline $90001951 \mathrm{~A}$ & 50 & $\begin{array}{l}\text { Young adult } \\
\text { male }\end{array}$ & Thebes & $\begin{array}{l}\text { Late Period to Ptolemaic } \\
\text { Period }\end{array}$ \\
\hline 90001169 & 41 & Adult male & Gournah & Graeco-Roman Period \\
\hline 90001258 & 40 & Adult female & Kom-Ombo & Ptolemaic to Roman Period \\
\hline 90001259 & 47 & Adult female & Unknown & $\begin{array}{l}\text { Late Period to Ptolemaic } \\
\text { Period }\end{array}$ \\
\hline 90001597 & 66 & Adult & Gournah & Unknown \\
\hline
\end{tabular}


Table 2: Compounds detected by elution order in mummies' balms. "V": presence, "-“: absence (MC: Monocarboxylic fatty acid, DC: Dicarboxylic fatty acid).

\begin{tabular}{|c|c|c|c|c|c|c|c|c|c|}
\hline \multirow[b]{2}{*}{ Compounds } & \multicolumn{9}{|c|}{ Samples } \\
\hline & 34 & 15 & 18 & 11 & 41 & 40 & 47 & 66 & 50 \\
\hline MC 8:0 & $\sqrt{ }$ & $\sqrt{ }$ & $\sqrt{ }$ & - & $\sqrt{ }$ & - & $\sqrt{ }$ & - & - \\
\hline glycerol & $\sqrt{ }$ & $\sqrt{ }$ & $\sqrt{ }$ & $\sqrt{ }$ & - & $\sqrt{ }$ & - & - & - \\
\hline DC 4 & - & - & $\sqrt{ }$ & - & - & - & $\sqrt{ }$ & $\sqrt{ }$ & - \\
\hline MC 9:0 & $\sqrt{ }$ & $\sqrt{ }$ & $\sqrt{ }$ & - & $\sqrt{ }$ & $\sqrt{ }$ & $\sqrt{ }$ & $\sqrt{ }$ & $\sqrt{ }$ \\
\hline DC 5 & - & - & - & - & - & - & $\sqrt{ }$ & $\sqrt{ }$ & - \\
\hline MC 10:0 & $\sqrt{ }$ & $\sqrt{ }$ & $\sqrt{ }$ & - & - & - & $\sqrt{ }$ & - & - \\
\hline DC 6 & - & - & $\sqrt{ }$ & - & $\sqrt{ }$ & - & $\sqrt{ }$ & $\sqrt{ }$ & - \\
\hline DC 7 & - & $\sqrt{ }$ & $\sqrt{ }$ & - & $\sqrt{ }$ & - & $\sqrt{ }$ & $\sqrt{ }$ & $\sqrt{ }$ \\
\hline MC 12:0 & - & $\sqrt{ }$ & $\sqrt{ }$ & - & - & - & $\sqrt{ }$ & - & - \\
\hline DC 8 & - & $\sqrt{ }$ & $\sqrt{ }$ & - & $\sqrt{ }$ & - & $\sqrt{ }$ & $\sqrt{ }$ & $\sqrt{ }$ \\
\hline MC 13:0 & - & - & - & - & $\sqrt{ }$ & - & $\sqrt{ }$ & - & - \\
\hline DC 9 & $\sqrt{ }$ & $\sqrt{ }$ & $\sqrt{ }$ & - & $\sqrt{ }$ & $\sqrt{ }$ & $\sqrt{ }$ & $\sqrt{ }$ & $\sqrt{ }$ \\
\hline MC 14:0 & $\sqrt{ }$ & $\sqrt{ }$ & $\sqrt{ }$ & $\sqrt{ }$ & $\sqrt{ }$ & $\sqrt{ }$ & $\sqrt{ }$ & $\sqrt{ }$ & $\sqrt{ }$ \\
\hline DC 10 & - & $\sqrt{ }$ & $\sqrt{ }$ & - & $\sqrt{ }$ & - & - & $\sqrt{ }$ & $\sqrt{ }$ \\
\hline MC 15:0 & - & $\sqrt{ }$ & - & $\sqrt{ }$ & $\sqrt{ }$ & - & - & - & $\sqrt{ }$ \\
\hline DC 11 & - & - & - & - & - & - & - & $\sqrt{ }$ & - \\
\hline MC 16:1 & - & - & - & - & - & - & - & $\sqrt{ }$ & - \\
\hline MC 16:0 & $\sqrt{ }$ & $\sqrt{ }$ & $\sqrt{ }$ & $\sqrt{ }$ & $\sqrt{ }$ & $\sqrt{ }$ & $\sqrt{ }$ & $\sqrt{ }$ & $\sqrt{ }$ \\
\hline DC 12 & - & - & - & - & - & - & - & $\sqrt{ }$ & - \\
\hline MC 17:0 & - & - & - & - & - & - & - & - & $\sqrt{ }$ \\
\hline MC 18:1 & $\sqrt{ }$ & - & $\sqrt{ }$ & $\sqrt{ }$ & - & $\sqrt{ }$ & - & - & $\sqrt{ }$ \\
\hline Retene & $\sqrt{ }$ & - & $\sqrt{ }$ & $\sqrt{ }$ & $\sqrt{ }$ & - & $\sqrt{ }$ & - & - \\
\hline MC 18:0 & $\sqrt{ }$ & $\sqrt{ }$ & $\sqrt{ }$ & $\sqrt{ }$ & $\sqrt{ }$ & $\sqrt{ }$ & $\sqrt{ }$ & $\sqrt{ }$ & $\sqrt{ }$ \\
\hline Pimaric Ac. & - & - & - & - & - & $\sqrt{ }$ & - & - & - \\
\hline Sandaracopimaric Ac. & - & - & - & - & - & $\sqrt{ }$ & - & - & - \\
\hline
\end{tabular}


Isopimaric Ac.

DHA

Abietic Ac.

3-hydroxy-DHA

7-hydroxy-DHA

15-hydroxy DHA

7-oxo-DHA

15-hydroxy-7-oxo DHA

MC 24:0

MC 26:0

Hopanes

Steranes

Cholesterol

Cholesta-3,5-dione

MC 28:0

MC 30:0

Unsaponified ester 